ournal for ImmunoTherapy of Cancer

\section{Phase I/II trial of a long peptide vaccine (LPV7) plus toll-like receptor (TLR) agonists with or without incomplete Freund's adjuvant (IFA) for resected high-risk melanoma}

\author{
Sapna P Patel (D , , Gina R Petroni, ${ }^{1}$ Jason Roszik, ${ }^{1}$ Walter C Olson, ${ }^{2}$ \\ Nolan A Wages, ${ }^{3}$ Kimberly A Chianese-Bullock, ${ }^{2}$ Mark Smolkin, ${ }^{3}$ Nikole Varhegyi, ${ }^{3}$ \\ Elizabeth Gaughan, ${ }^{2}$ Kelly T Smith, ${ }^{2}$ Kathleen Haden, ${ }^{2}$ Emily H Hall, ${ }^{2}$ \\ Sacha Gnjatic, ${ }^{4}$ Patrick Hwu, ${ }^{5}$ Craig L Slingluff (1) ${ }^{6}$
}

To cite: Patel SP, Petroni GR, Roszik J, et al. Phase I/II trial of a long peptide vaccine (LPV7) plus toll-like receptor (TLR) agonists with or without incomplete Freund's adjuvant (IFA) for resected high-risk melanoma. Journal for ImmunoTherapy of Cancer 2021;9:e003220. doi:10.1136/ jitc-2021-003220

- Additional supplemental material is published online only. To view, please visit the journal online (http://dx.doi.org/10. 1136/jitc-2021-003220).

Accepted 29 June 2021

A Check for updates

(c) Author(s) (or their employer(s)) 2021. Re-use permitted under CC BY. Published by BMJ.

For numbered affiliations see end of article.

\section{Correspondence to} Craig L Slingluff; CLS8H@hscmail.mcc.virginia. edu

\section{ABSTRACT}

Background We performed a clinical trial to evaluate safety and immunogenicity of a novel long peptide vaccine administered in combinations of incomplete Freund's adjuvant (IFA) and agonists for TLR3 (polyICLC) and TLR7/8 (resiquimod). We hypothesized that $\mathrm{T}$ cell responses to minimal epitope peptides (MEPs) within the long peptides would be enhanced compared with prior vaccines with MEP themselves and that T cell responses would be enhanced with TLR agonists, compared with IFA alone. Methods Participants with resected stage IIB-IV melanoma were vaccinated with seven long melanoma peptides (LPV7) from tyrosinase, gp100, MAGE-A1, MAGE-A10, and NY-ES0-1, each containing a known MEP for $\mathrm{CD}^{+} \mathrm{T}$ cells, plus a tetanus helper peptide (Tet) restricted by Class II MHC. Enrollment was guided by an adaptive design to one of seven adjuvant combinations. Vaccines were administered at weeks 1, 2, 3, 6, 9, 12 at rotating injection sites. $T$ cell and $\lg G$ antibody $(A b)$ responses were measured with IFN-gamma ELIspot assay ex vivo and ELISA, respectively.

Results Fifty eligible participants were assigned to seven study groups, with highest enrollment on arm $\mathrm{E}$ (LPV7+Tet+IFA+polylCLC). There was one dose-limiting toxicity (DLT) in Group E (grade 3 injection site reaction, $6 \%$ DLT rate). All other treatment-related adverse events were grades $1-2$. The $\mathrm{CD}^{+} \mathrm{T}$ cell immune response rate (IRR) to MEPs was $18 \%$, less than in prior studies using MEP vaccines in IFA. The $\mathrm{CD}^{+} \mathrm{T}$ cell IRR trended higher for IFA-containing adjuvants (24\%) than adjuvants containing only TLR agonists (6\%). Overall T cell IRR to full-length LPV7 was 30\%; CD4 ${ }^{+}$T cell IRR to Tet was $40 \%$, and serum Ab IRR to LPV7 was $84 \%$. These IRRs also trended higher for IFA-containing adjuvants ( $36 \%$ vs $18 \%$, $48 \%$ vs $24 \%$, and $97 \%$ vs $60 \%$, respectively).

Conclusions The LPV7 vaccine is safe with each of seven adjuvant strategies and induced T cell responses to CD8 MEPs ex vivo in a subset of patients but did not enhance IRRs compared with prior vaccines using short peptides. Immunogenicity was supported more by IFA than by TLR agonists alone and may be enhanced by polyICLC plus IFA.
Trial registration number NCT02126579.

\section{INTRODUCTION}

Antibodies to CTLA-4 and to PD-1 are approved for adjuvant therapy after surgery for stage IIIB-IV melanoma; however, treatmentassociated toxicities can be serious, ${ }^{1}$ and this limits use in earlier stage patients. Thus, there is a need for immune therapies with low toxicity that can target cancer cells with specificity. Melanoma vaccines have promise as an alternative strategy to elicit active antitumor immune responses. Minimal epitope peptides (MEPs) for melanoma-reactive $\mathrm{T}$ cells were identified in the 1990s from shared melanoma antigens (eg, tumor associated antigens MART-1/MelanA, gp100, and tyrosinase) and from cancer testis antigens (eg, NY-ESO-1, MAGE-A1, and MAGE-A10). ${ }^{2}$ Clinical activity has been observed with a vaccine targeting gp100, and with adoptive cell therapies targeting MAGE-A3 and NY-ESO- $1 ;^{3-6}$ however, immune responses to vaccines using short peptides can be transient and of low magnitude, limiting their long-term clinical activity. $^{78}$ This may be due to inadequate vaccine adjuvants or to limitations intrinsic to short peptides. Contemporary evidence suggests that vaccination with long peptides (30-mers) may be a more effective strategy to elicit a meaningful immune response. ${ }^{9}$ This approach, combined with incomplete Freund's adjuvant (IFA), has induced clinical regressions of squamous vulvar neoplasia. ${ }^{10}$ Thus, one goal of the present trial was to assess whether vaccination with long (30mer) peptides encompassing MEPs for $\mathrm{CD}^{+}$ 
$\mathrm{T}$ cells would be safe and effective for induction of $\mathrm{T}$ cell responses to those MEPs. Most prior studies with long peptides in cancer have been limited to those targeting the NY-ESO-1 protein and HPV proteins. ${ }^{11-13}$ The present first-in-human study reports the safety and immunogenicity of multiple long peptides from MAGE proteins and melanocytic antigens.

Vaccines require immunologic adjuvants to induce strong immune responses. A common adjuvant for peptide vaccines has been IFA, in particular Montanide ISA-51, which consists of mineral oil and an emulsifying agent and which has been active in a wide range of human clinical trials of cancer vaccines using short or long peptides. ${ }^{10}{ }^{12} 14-16$ Murine data have challenged the use of IFA with short peptides, ${ }^{8}$ but our own more recent human experience supports use of IFA to enhance the magnitude and persistence of $\mathrm{T}$ cell responses. ${ }^{17}{ }^{18}$ Tolllike receptor (TLR) agonists can potentiate antitumor T-cell responses. ${ }^{11} 12$ 18-20 The TLR3 agonist polyinosinicpolycytidylic acid, stabilized with polylysine and carboxymethylcellulose (polyICLC), preferentially activates $\mathrm{BDCA}^{+}$myeloid dendritic cells (mDC), supporting the production of IFN $\beta$, CXCL10, and IL12p70. ${ }^{21}$ It has been safely administered with peptides in an emulsion with IFA and has enhanced $\mathrm{T}$ cell and antibody (Ab) responses. ${ }^{12}{ }^{17}$ Resiquimod is an agonist for TLR7 and TLR8 which activates plasmacytoid, ${ }^{22}$ supports differentiation and increased function of $\mathrm{mDC}^{23}$ and reduces proliferation of regulatory $\mathrm{T}$ cells. ${ }^{24}{ }^{25}$ It has been used as a topical gel formulation in murine ${ }^{26}$ and human studies. ${ }^{2427}$ Preclinical studies support combining agonists for TLR3 and TLR7/8 for synergistic activation of both $\mathrm{CD}^{+} \mathrm{c}^{+} \mathrm{mDC}$ and $\mathrm{CD} 141^{+} \mathrm{mDC}^{28}$ and for promoting differentiation of Th1 $\mathrm{CD}^{+}{ }^{+} \mathrm{T}$ cell responses and $\mathrm{B}$ cell responses. ${ }^{29}$ Thus, there is rationale for using polyICLC and resiquimod alone or together, and with IFA, as adjuvants for long peptide vaccines.

We have assessed the safety and immunogenicity of seven long peptides plus IFA, the TLR3 agonist polyICLC, and/or a TLR7/8 agonist resiquimod in seven different adjuvant combinations, using an adaptive study design. ${ }^{30}$ The long peptides represent portions of melanocytic differentiation antigens and cancer-testis antigens, each 29-31 amino acids long, and each incorporating a defined MEP for CD8 T cells (table 1). A central hypothesis was that vaccination with the long peptide vaccine (LPV7) would induce stronger $\mathrm{T}$ cell responses to the MEPs than observed in prior vaccines with MEPs themselves. ${ }^{15}$ It was also anticipated that these long peptides would induce $\mathrm{CD}^{+}$helper $\mathrm{T}$ cell responses. A peptide from tetanus toxoid, known to induce $\mathrm{CD} 4^{+} \mathrm{T}$ cell responses ${ }^{15}$ was included as well, both to support T cell responses to LPV7 and also to be evaluable for the impact of each adjuvant combination.

\section{METHODS \\ Participant selection}

This was an open-label, phase I/II adaptive design study of LPV7 \pm IFA and TLR agonists in participants with resected Stage IIB-IV melanoma. The protocol is provided as online supplemental material 1 . The primary objective was to assess safety of each vaccine combination. A secondary objective was to estimate the immunogenicity of LPV7 in each of the seven adjuvant preparations, with an expectation that $\mathrm{CD}^{+} \mathrm{T}$ cell responses to the embedded short peptides would be enhanced compared with prior vaccines with short peptides themselves. A summary goal was to determine the optimal vaccine plus adjuvant combination based on safety and immunogenicity.

Patients were eligible if 18 years or older, with ECOG performance status of $0-1$ and Stage IIB-IV melanoma (AJCC 7th edition, at original diagnosis or recurrence), rendered clinically free of disease by surgery or other therapy or by spontaneous remission within 6 months of study entry. Patients with brain metastases were eligible if they had had no more than three lesions, none $>2 \mathrm{~cm}$ in diameter at the time of protocol entry, all completely removed or treated. Eligible patients must have had at least one intact axillary or inguinal node basin. The study

Table 17 long melanoma peptides used in the vaccines, with the corresponding defined MEPs restricted by MHC Class I

\begin{tabular}{|c|c|c|c|}
\hline \multirow{2}{*}{$\begin{array}{l}\text { Restricting class I } \\
\text { MHC allele }\end{array}$} & \multirow{2}{*}{$\begin{array}{l}\text { Short peptides } \\
\text { Minimal epitope }\end{array}$} & \multicolumn{2}{|c|}{ Long peptide (30-mers) in LPV7 for the present proposal } \\
\hline & & Sequence (minimal epitope underlined) & Source (\# residues) \\
\hline HLA-A1 & Tyrosinase ${ }_{240-251 S}{ }^{*}$ & FTIPYWDWRDAEKSDICTDEYMGGQHPTN & $\begin{array}{l}\text { Tyrosinase } \\
\text { (291-259 s }\end{array}$ \\
\hline \multirow[t]{2}{*}{ HLA-A2 } & Tyrosinase $_{369-377} \dagger$ & SMHNALHIYMDGTMSQVQGSANDPIFLLHH & Tyrosinase $_{361-390} \uparrow(30)$ \\
\hline & gp100 $209-217-2 \mathrm{M}$ & VPLAHSSSAFTIMDQVPFSVSVSQLRALDG & ${\mathrm{gp} 100_{198-227}} \ddagger(30)$ \\
\hline \multirow[t]{2}{*}{ HLA-A3 } & 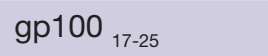 & LLHLAVIGALLAVGATKVPRNQDWLGVSRQL & $g_{p 100}{ }_{9-39}(31)$ \\
\hline & MAGE-A1 ${ }_{96-104}$ & SREEEGPSTSCILESLFRAVITKKVADLVG & MAGE-A1 ${ }_{82-111}(30)$ \\
\hline HLA-B35/B51 & NY-ESO-1 $94-102$ & GARGPESRLLEFYLAMPFATPMEAELARRS & NY-ESO-1 ${ }_{79-108}(30)$ \\
\hline
\end{tabular}

*Substitution of $\mathrm{S}$ for $\mathrm{C}$ at residue 244.

†Post-translational change of $\mathrm{N}$ to $\mathrm{D}$ at residue 371 .

$\ddagger 209-2 M$, substitution of $M$ for $T$ at position 210 . The minimal epitope peptides are abbreviated in figures based on the first 3-4 letters. 


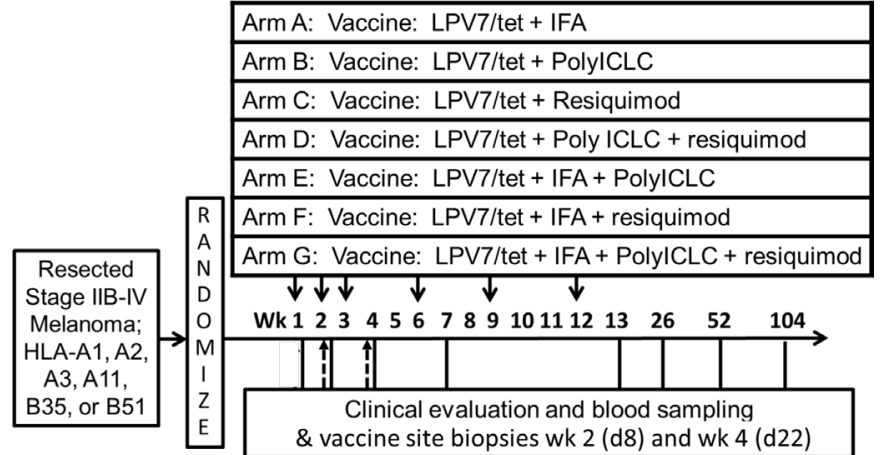

Figure 1 Mel60 protocol schema. Participants with resected high-risk melanoma were randomized among seven study arms in an adaptive design. Each was vaccinated at weeks 1, $2,3,6,9$, and 12 in an extremity (50\% id/50\% sc) with LPV7 plus Tet (solid arrows). PolyICLC (1 mg) was incorporated in the peptide/adjuvant emulsion or mixtures and injected at the vaccine site. Resiquimod cream was administered topically at the vaccine site, $112.5 \mathrm{mcg}$. Blood was drawn at weeks 1 , $2,4,7,13,26,52$, and 104. Vaccine sites were biopsied on days 8 and 22 (dotted line arrows).

was limited to patients expressing HLA-A1, A2, A3, B35, or B51. Ocular primary melanoma patients were not eligible.

\section{Vaccine and adjuvant selection}

Six peptides from gp100, tyrosinase, MAGE-A1, and MAGE-A10 proteins were selected based on high immunogenicity in prior clinical trials using MEPs for $\mathrm{CD}^{+} \mathrm{T}$ cells $^{141531}$ restricted by HLA-A1, A2, or A3: long peptides encompassing those MEPs were constructed. Also, the NY- ESO-1 ${ }_{94-102}$ peptide, containing a MEP for $\mathrm{CD}^{+} \mathrm{T}$ cells restricted by HLA-B35 and B51, was selected based on immunogenicity in a prior trial and. ${ }^{12}$ The sequences and known immunogenic MEP for each peptide are listed in table 1 .

Montanide ISA-51 was purchased from Seppic Inc (Fairfield, New Jersey, USA) as cGMP material in sterile vials. PolyICLC was provided as a clinical grade reagent (Hiltonol; Oncovir, Washington, DC, USA) by the Ludwig Institute for Cancer Research and its Cancer Vaccine Consortium. Resiquimod was provided by 3M Pharmaceuticals (St Paul, Minnesota, USA).

\section{Study regimen}

Participants were vaccinated with LPV7 (300 mcg long peptide/dose) plus Tet (200 mcg/dose) on the schedule shown in figure 1 . Tet was included to provide a stimulus for helper $\mathrm{T}$ cell responses to support $\mathrm{CD}^{+} \mathrm{T}$ cell responses, ${ }^{14} 1532$ because the extent of $\mathrm{CD}^{+} \mathrm{T}$ cell response to LPV7 was not known in advance. Participants were adaptively assigned to one of seven adjuvant combinations (figure 1 and online supplemental table 1) and were enrolled at two institutions. The adaptive assignment included equal randomization and allocation among allowable arms until a weighted allocation scheme or the modeling stage was triggered. Vaccine sites were rotated between upper arm and thigh, avoiding any extremity that had undergone lymph node removal. Each vaccine was administered in one skin site, with $1 \mathrm{~mL}$ volume injected into subcutaneous (sc) tissue and $1 \mathrm{~mL}$ volume injected intradermally (id), through the same skin puncture site. Each participant underwent three $4 \mathrm{~mm}$ punch biopsies of skin at the vaccine injection site at days 8 and 22. Control biopsies of normal skin were also collected at these time points for the first six participants enrolled.

\section{Safety and toxicity}

Adverse events (AEs) were collected continuously from the time of first injection to study completion and the AEs were graded using NCI CTCAE V.4.03. Doselimiting toxicities (DLTs) were defined as any unexpected, treatmenft-related $\mathrm{AE}$ that was $\geq$ Grade 1 ocular AE, $\geq$ Grade 2 allergic/autoimmune reaction, or $\geq$ Grade 3 (any) except for Grade 3 injection site reaction (ISR) with ulceration $\leq 2 \mathrm{~cm}$.

\section{Immunologic response}

Peak $\mathrm{CD}^{+}$and $\mathrm{CD}^{+} \mathrm{T}$ cell responses in the peripheral blood were evaluated by direct (ex vivo) ELIspot assay for IFN-gamma, as reported. ${ }^{14}$ This was performed in a core laboratory dedicated to immune monitoring, with standard operating procedures and quality assurance measures. ${ }^{14}$ Participants were evaluable for immune response if at least one post-treatment sample was measurable for response. A minimum of 4 weeks of data was used to guide decisions about the range of optimal dose combinations. Durability of $\mathrm{T}$ cell responses was assessed at 26 weeks and for longer intervals when available, with the hypothesis that durability of $\mathrm{T}$ cell responses would be enhanced compared with prior experience with short peptides and would be improved with TLR agonists when compared with IFA alone in this study.

The short peptides (9-12 amino acids long) contained within each long peptide (table 1 , underlined) represent MEPs for $\mathrm{CD}^{+} \mathrm{T}$ cells. A $\mathrm{CD}^{+} \mathrm{T}$ cell response to these peptides was defined as at least a twofold increase in IFNgamma-secreting cells over background (maximum of 2 negative controls) and over pre-existing responses at baseline, an increase over background of at least 20 IFNgamma secreting cells per $100,000 \mathrm{CD}^{+} \mathrm{T}$ cells, and no overlap in SD with the negative control, as described. ${ }^{14}$ $\mathrm{A} \mathrm{CD} 4^{+} \mathrm{T}$ cell response to the Tet was defined similarly but with at least 20 IFN-gamma secreting cells per $100,000 \mathrm{CD}^{+} \mathrm{T}$ cells. A T cell response to the full-length LPV7 required an increase over background of at least 10 IFN-gamma secreting cells per 100,000 total peripheral blood mononuclear cells (PBMC). Immune response rate (IRR) is defined as the proportion of subjects with a T-cell immune response and is reported as a point estimate with 90\% CIs.

Interassay coefficients of variation (CVs) were calculated for the ELIspot response of two normal donors to a pool of viral peptides (CEF peptide pool $^{33}$ ): for the high and low responders, mean numbers of spots per 200,000 
cells were 271 and 42, respectively, and CVs were $28 \%$ and $26 \%$, respectively.

\section{Serum antibody responses to LPV7 long peptides}

Sera were evaluated by ELISA for IgG Ab to the LPV7 peptide pool at weeks $1,7,13$, and 26, using methods described. $^{12}$ Briefly, 96-well half-area cluster plates (Corning Costar) were coated with $30 \mathrm{mcL}$ of LPV7 peptides (pooled) diluted in carbonate/bicarbonate buffer ( $\mathrm{pH}$ 9.4; Sigma-Aldrich) at $1.67 \mathrm{mcg} / \mathrm{mL}$ of each peptide. For quantitation of specific serum levels of antipeptide Ab, purified IgG immunoglobulin (Fitzgerald Industries International) was prepared in coating buffer at $1 \mathrm{mcg} / \mathrm{mL}$, serially diluted fourfold to $0.25 \mathrm{ng} / \mathrm{mL}$, and $30 \mathrm{mcL}$ of each dilution added to duplicate wells. After incubation overnight at $4^{\circ} \mathrm{C}$, plates were washed with phosphate-buffered saline (PBS) with $0.1 \%$ Tween 20 (TPBS), then blocked 1 hour with $5 \%$ nonfat dry milk in TPBS (blocking 143 buffer). Beginning at 1:100, fourfold serial dilutions of participant and control sera were prepared in blocking buffer and added to individual wells. After 2 hours at room temperature (RT) and washing, secondary Ab (goat anti-human IgG AP conjugate, Southern Biotech) was added to all wells, incubated 1 hour at RT, then washed. Attophos substrate (Sigma) was added to each well for $30 \mathrm{~min}$. $3 \mathrm{~N} \mathrm{NaOH}$ was added to stop the reaction, and fluorescence was recorded on a Molecular Devices SPECTRAmax Gemini EM Fluorescent plate reader, excitation $450 \mathrm{~nm}$, emission $580 \mathrm{~nm}$. The FORECAST function in Microsoft Excel was used to calculate the Ab titer of participants' sera, ${ }^{12}$ which was defined as the reciprocal of the serum dilution that yields a fluorescent intensity 10 times greater than the cut-off value. The cut-off value was defined as the average fluorescence obtained from the first four dilutions of serially diluted normal donor serum (negative control). Ab titers $\geq 100$ were considered positive. For participants with $\mathrm{Ab}$ titers that were $>100$ in prevaccine sera, a vaccineassociated response also required a titer increase of at least 10 -fold $(1 \log )$.

\section{Statistical considerations}

The study was designed with two stages. The initial stage accrued participants in cohorts of one per arm (randomized within a zone) until a participant experienced a DLT. The escalation plan for the first stage was based on grouping treatment combinations into three zones (online supplemental table 1), beginning with Zone 1. With this dose-escalation design, participants could be accrued and assigned to other open combinations within a zone, but escalation would not occur outside the zone until the minimum follow-up period of 3 weeks was observed for the first participant accrued to a combination. A continual reassessment method (CRM) ${ }^{34} 35$ directed enrollment in the second stage. This method used a selected set of possible orderings of combinations for the DLT probabilities and a working model for the DLT probabilities under each ordering. The CRM model was used to fit the working model with the accumulated data. In the event of a tie between the likelihood values of two or more orderings, then the selected order of combinations was chosen at random from among the tied orderings. The DLT probabilities defined a set of acceptable combinations with a toxicity tolerance of $33 \%$. Assuming at least one optimal combination existed, up to 52 evaluable participants could have been accrued to determine the optimal combination. Simulation results were run to display the performance of the design characteristics, which have been reported. ${ }^{36}$ Immune responses were assessed overall, but differences between enrolling institutions were also explored in the context of data on PBMC function.

The study was not designed to make statistical comparisons between arms. Frequency and magnitude of treatment-related adverse events (TRAEs) were summarized by arm. IRR for defined categories was estimated as point estimates with $90 \%$ exact CIs. Graphical representations were used to present study outcomes. Fisher's exact test was used to assess associations of maximum immune response to maximum TRAE grade and other select AEs. Disease-free survival was defined from start of treatment to recurrence/progression or death from any cause, whichever occurred first. Participants who did not experience an event were censored at date of last contact. Overall survival was defined as the time from start of treatment to time of death from any cause. Disease-free survival and overall survival distributions were estimated by the product-limit method of Kaplan and Meier.

\section{RESULTS \\ Participant characteristics}

Total enrollment was 51 participants; however, one did not receive study treatment. Thus, demographic, safety, and immunologic data are reported for 50 participants who were enrolled and treated. These included 30 males $(60 \%)$ and 20 females $(40 \%)$, with 5, 7, 4, 6, 16, 6, and 6 treated on arms A-G, respectively (online supplemental file 1, CONSORT diagram). Most patients had Eastern Cooperative Oncology Group (ECOG) performance status (PS) of $0(90 \%)$ and stage III disease at registration $(82 \%)$. Details are provided in online supplemental table 2. Four patients experienced new metastatic disease on study (arms D (1), E (1), G (2)), but two of them had received all six vaccines (arms E and G): the others received three and four vaccines, respectively; so, all 50 were evaluable for toxicity, immune responses, and clinical outcomes (online supplemental file 1, CONSORT diagram).

\section{Toxicities and adverse events}

There was one DLT across all groups: Group E (Grade 3 ISR, 6\% in that group), after receiving all six vaccines. All other AEs were Grades 1-2; most common were ISR $(90 \%)$, fatigue $(62 \%)$, skin induration $(56 \%)$, chills $(48 \%)$, fever, myalgia, and headache $(30 \%)$, and were 

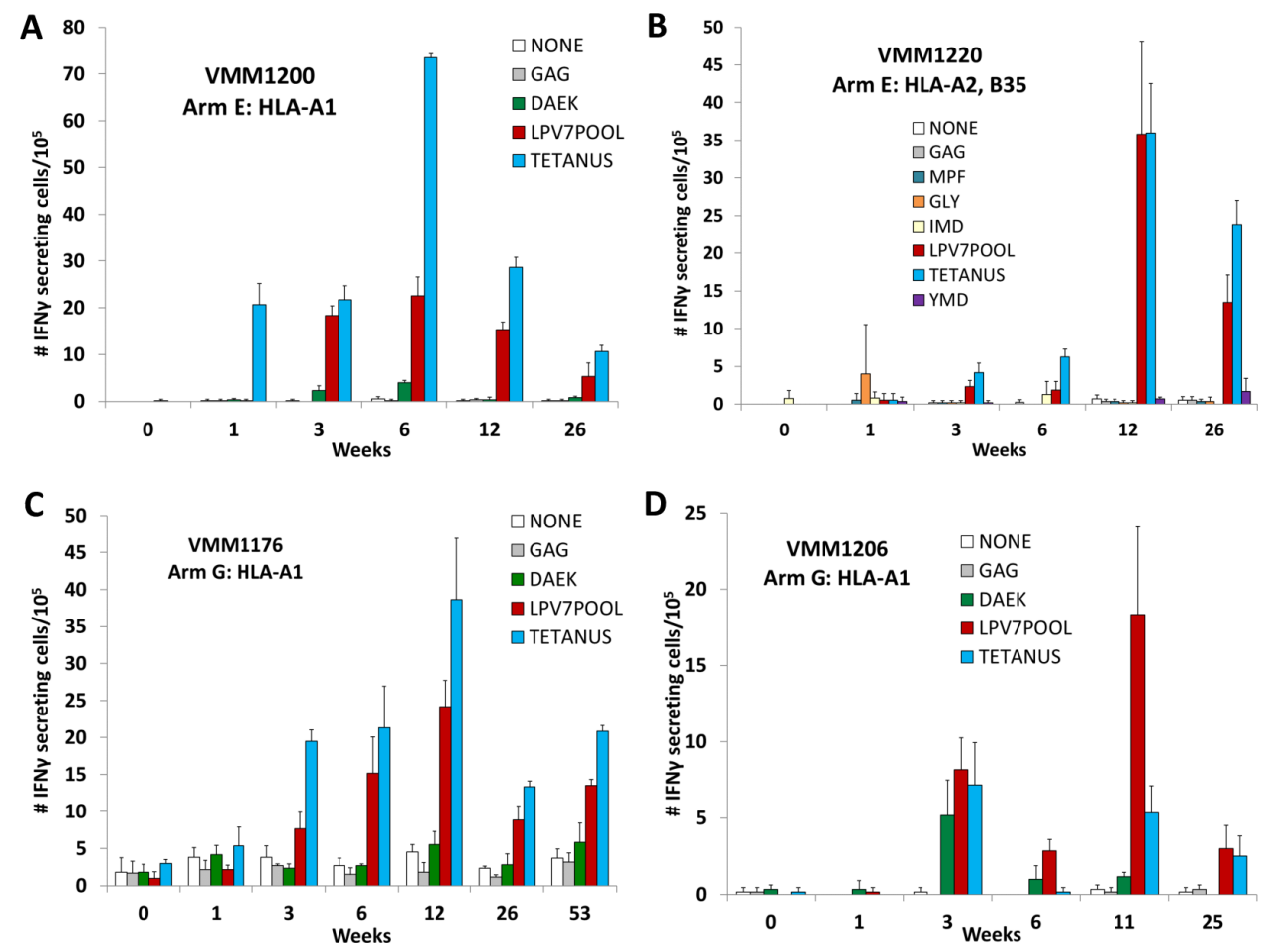

Figure 2 Examples of $T$ cell responses by ex vivo ELlspot assay for two participants on arm $E(A, B)$ and two on arm $G(C, D)$. The number of cells secreting IFN-gamma in response to the pool of LPV7 peptides (LPV7POOL), Tetanus peptide, or individual MEPs (DAEK in A, C, D; MPF, GLY, IMD, YMD in B) are shown with bar graphs plus SD of replicate values. White and gray bars represent background (negative control) reactivity at each time point. The magnitude of response has not been adjusted for the per cent of CD8 T cells (for MEP) or for the per cent of CD4 T cells for tetanus peptide. MEP, minimal epitope peptide.

similar across groups, but lower for Group C (online supplemental table 3). No study combinations crossed the statistical boundaries for unacceptable toxicity.

\section{Immune responses to vaccines}

T cell response to LPV7

By ex vivo ELIspot assay, immune responses to one of the seven long peptides individually or to the LPV7 pool, were observed in 15 subjects (30\%, 90\% CI 19 to 42). Example data for four participants are shown in figure 2 , with some persisting to the last time point tested (figure 2B,C). The best IRRs to LPV7 were $67 \%$ (G), 40\% (A), and $31 \%$ (E), with wide CIs (table 2). Among seven patients in whom $\mathrm{T}$ cell responses were detected to one or more of the individual long peptides, the most immunogenic were gp100 ${ }_{9-39}$ and NY-ESO-1 ${ }_{79-108}$ (5 and 3, respectively, table 2, rightmost column). The peak $\mathrm{T}$ cell responses to LPV7 are summarized for each study arm in figure 3 .

\section{CD8 $\mathrm{T}$ cell response to MEPs epitopes}

Each of the seven long peptides contained an MEP for CD8 T cells restricted by HLA-A1, A2, A3, B35, or B51 (table 1). $\mathrm{T}$ cell responses to these MEPs were assessed singly or as peptide pools by ex vivo ELIspot assay for each patient with the appropriate HLA expression. Example data for a $\mathrm{T}$ cell response to the MEP tyrosinase ${ }_{240-251 \mathrm{~S}}$ (DAEK) are shown in figure 2D; however, the data in that plot represent raw values before adjusting for the percent of $\mathrm{CD} 8^{+}$ $\mathrm{T}$ cells in the PBMC. After that adjustment, there were
56.2 IFN-gamma-secreting cells per 100,000 CD $8^{+} \mathrm{T}$ cells, with negative control values of 3.0 (not shown). Overall, $\mathrm{CD}^{+} \mathrm{T}$ cell responses were detected to MEPs in 9 patients $(18 \%, 90 \%$ CI 10 to 29$)$ with the best IRRs of $40 \%$ and $25 \%$ in arms A and E, respectively (table 2). The magnitude of those T cell responses to MEPs is shown by arm in figure 3. Among the nine participants with responses to MEPs, six had responses both to individual peptides and to the MEP pool, two had responses just to the pool, and one responded to an individual peptide. Responses to individual peptides were detected to tyrosinase ${ }_{240-251 \mathrm{~S}}$, NY-ESO-1 ${ }_{94-102}$, gp100 ${ }_{17-25}$, and MAGE-A1 ${ }_{96-104}$ in four, two, one, and one patient, respectively, which represent $19 \%$, $17 \%, 5 \%$, and $5 \%$ of participants with the corresponding Class I MHC. In a prior trial using 12 MEPs+Tet+IFA in 41 participants (Mel44 trial, NCT00118274), $\mathrm{CD}^{+} \mathrm{T}$ cell responses were detected ex vivo to six of the MEPs using the same assay criteria. The IRRs to those six peptides in the prior study ranged from $4 \%$ to $78 \%$, but IRRs to those same peptides in the present study ranged from $0 \%$ to $19 \%$. Differences between IRR to these peptides between the studies ranged from $4 \%$ to $78 \%$ (online supplemental table 4).

\section{Helper T cell response to tetanus peptide}

Immune responses to the Tet peptide provide another measure of immunogenicity with each adjuvant preparation. Example data for responses in four patients are 


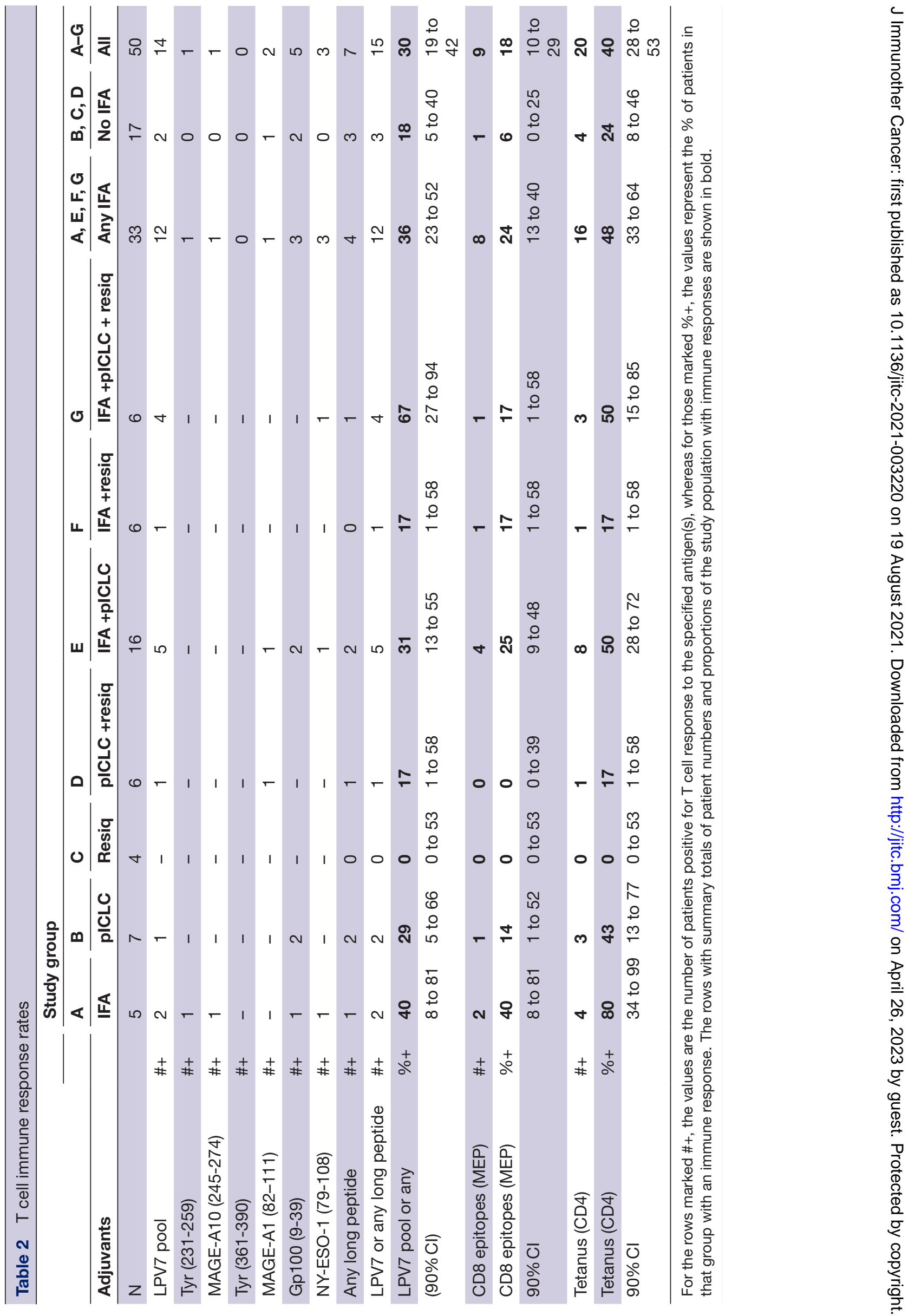


A

$A$
0
0
0
0
0
0
0
0
0
0
0
0
0
0
0
0
0
0
0
0

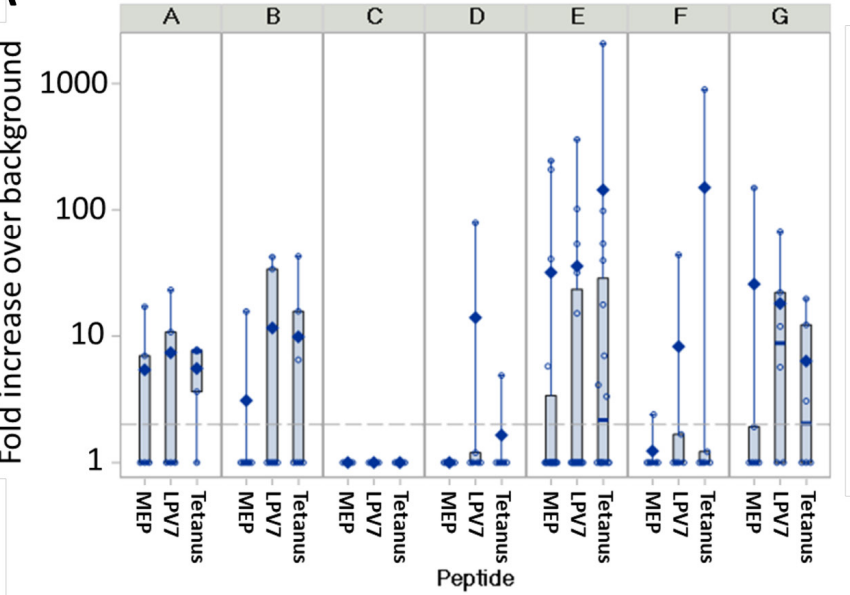

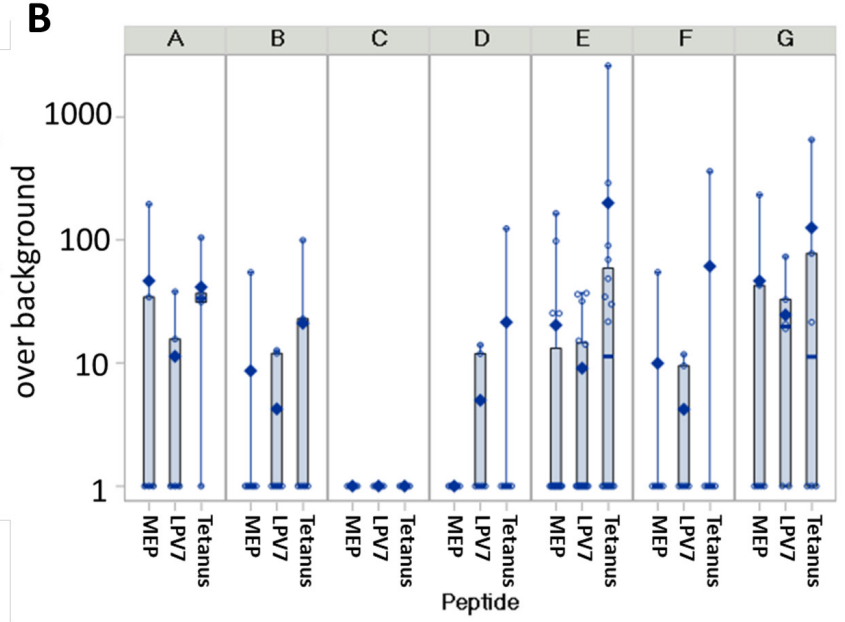

Figure 3 Summary T cell response data. The maximum T cell response for each patient, by study arm shown on the top of the panel, is shown in (A) as fold-increase over background, and in (B) as increase in IFN-gamma-producing T cells per $100,000 \mathrm{CD}^{+} \mathrm{T}$ cells for short peptides (MEP), per 100,000 total PBMC for long peptides (LPV7), and per 100,000 CD4 ${ }^{+} \mathrm{T}$ cells for tetanus peptide (Tet). In (B), the values are modified by adding 1 to enable plotting zero values as 1 on a log scale. Bottom (25th percentile) and top (75th percentile) of the box represents the IQR, the thick horizontal line inside represents the median value. The diamond represents the mean, and the vertical line extends to the minimum and maximum observations outside of the IQR. The dashed reference line in panel A) indicates the twofold threshold for positivity. MEP, minimal epitope peptide.

shown in figure 2. Overall, responses were detected in 20 subjects $(40 \%, 90 \%$ CI 28 to 53), with the highest IRRs of $80 \%$ in Arm A, $50 \%$ in Arms E and G, and $43 \%$ in Arm B (table 2). Data for immune response magnitude are summarized in figure 3 .

\section{Immune response rates associated with adjuvant components}

This study was not designed to make comparisons among arms, but an exploratory assessment shows that the overall proportion of patients with $\mathrm{T}$ cell responses to MEPs, LPV7, and Tet trended higher for adjuvants containing IFA (arms A, E, F, G, n=33) than for those without IFA (IFA (arms B-D, n=17, table 2 and figure 4A). Adjuvants containing polyICLC yielded IRRs trending slightly higher than those without polyICLC for LPV7 and tetanus, but not for the short peptides. There was a trend to lower IRRs with adjuvants containing resiquimod versus those without resiquimod (figure 4A). For participants receiving IFA-containing vaccines, $T$ cell responses were detected at more time points during the study (figure 4B), to more peptides (figure 4C), and with higher fold-increase and absolute magnitude of $\mathrm{T}$ cell response (figure 4D-E).

\section{Concordance of T cell responses to MEPs, LPV7, and Tet}

Overall, 26 participants $(52 \%)$ had immune responses to short peptides, LPV7, and/or Tet. Of the nine with $\mathrm{T}$ cell responses to short peptides, five $(56 \%)$ also had responses to LPV7, and seven $(78 \%$ ) also had responses to Tet. Of 15 with responses to LPV7, 5 had responses to the short peptides and 10 had responses to Tet.

\section{Associations of $\mathrm{T}$ cell responses with treatment-related adverse events}

As shown in online supplemental figure 1A, participants with higher grade 2/3 TRAEs had greater magnitude
T cell responses to LPV7 $(p=0.014)$, Tet $(p=0.022)$, and MEP $(p=0.068)$ by Fisher's exact test. Also, grade 2/3 ISR (vs grade $0 / 1$ ) was associated with higher immune response to MEP, LPV7, and Tet ( $p=0.008$, 0.002, 0.009, respectively; Online supplemental figure 1B). Grade 2 induration at injection sites (vs $0 / 1$ ) was associated with higher magnitude $\mathrm{T}$ cell responses to LPV7 $(\mathrm{p}=0.001)$ and to Tet $(p=0.002)$, but not to MEPs $(p=0.4)$ (online supplemental figure $1 \mathrm{C}$ ).

\section{Antibody responses to LPV7}

IgG Ab responses to LPV7 were evaluated in 44 of the 50 participants. The induced IgG titers were highest in arms $\mathrm{E}$ and $\mathrm{G}$ and lowest in $\mathrm{B}$ and $\mathrm{C}$ (figure $5 \mathrm{~A}-\mathrm{C}$ ). The proportions of participants with serum IgG response by week 7 were $0 \%, 20 \%, 43 \%, 50 \%, 75 \%, 83 \%$, and $100 \%$ for arms C, A, B, D, G, F, and E, respectively, and increased by week 26\%-100\% for arms D-G, 80\% for arm A, 57\% for arm B, $25 \%$ for arm C, and $84 \%$ overall (figure $5 \mathrm{D}$ ). For IFAcontaining adjuvants, $\mathrm{Ab}$ responses were observed in $79 \%$ by week 7 and $97 \%$ overall. On the other hand, for adjuvants without IFA, Ab responses were observed in $33 \%$ by week $7 \%$ and $60 \%$ overall. IgG responses to Tet were also observed for $12 / 44$ evaluable subjects (27\%), including $75 \%(3 / 4)$ on arm G, 50\% (7/14) on arm E, and one each on arms $\mathrm{D}$ and $\mathrm{F}$ (data not shown). IgG responses to HIV gag were assessed as negative controls with $42 / 44$ $(95 \%)$ negative and only 2 having low level titers (max 808 and 162) that presumably represent false positives (data not shown).

\section{T cell responses to peptides by enrolling institution}

The overall immune response evaluation was performed for the full dataset in accord with the study design. 

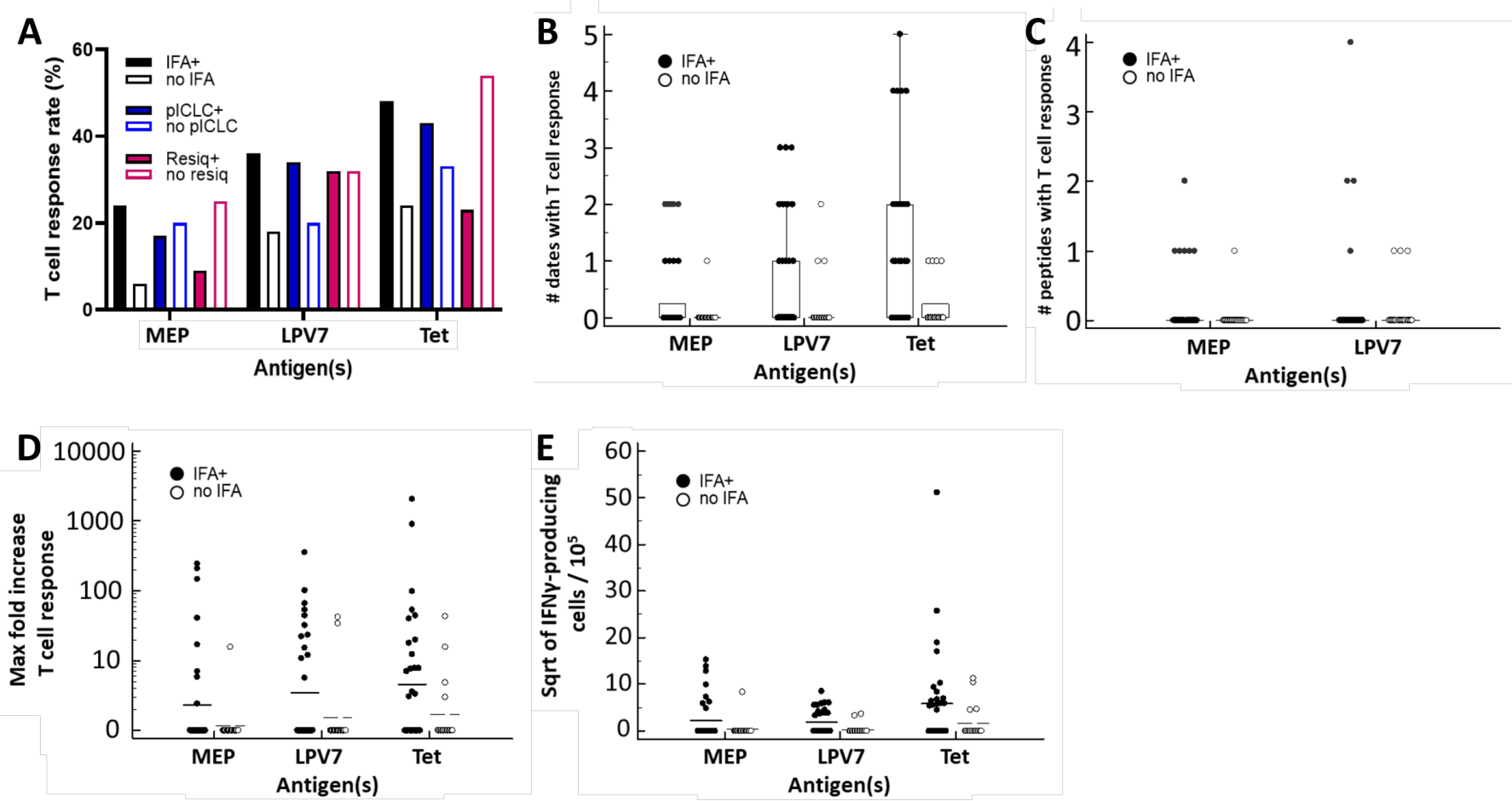

Figure 4 Immune responses after vaccination with adjuvants containing IFA or note containing IFA. The overall T cell response rates to MEPs, LPV7, and Tet are shown for groups based on the adjuvant used (A). Also, panels B-E show for participants vaccinated with IFA-containing adjuvants (groups $A, E, F, G ; n=33$ ) and participants vaccinated with adjuvants lacking IFA (groups B-D; $n=17$ ), the per cent with immune responses to short peptides, LPV7, and Tet are shown (A), as well as the number of dates per participant with an immune response (B), number of peptides with immune response per participant (C), maximum fold increase (D), and the square root of the maximum number of IFN-gamma-secreting cells per $10^{5}(\mathrm{E})$. MEP, minimal epitope peptide.
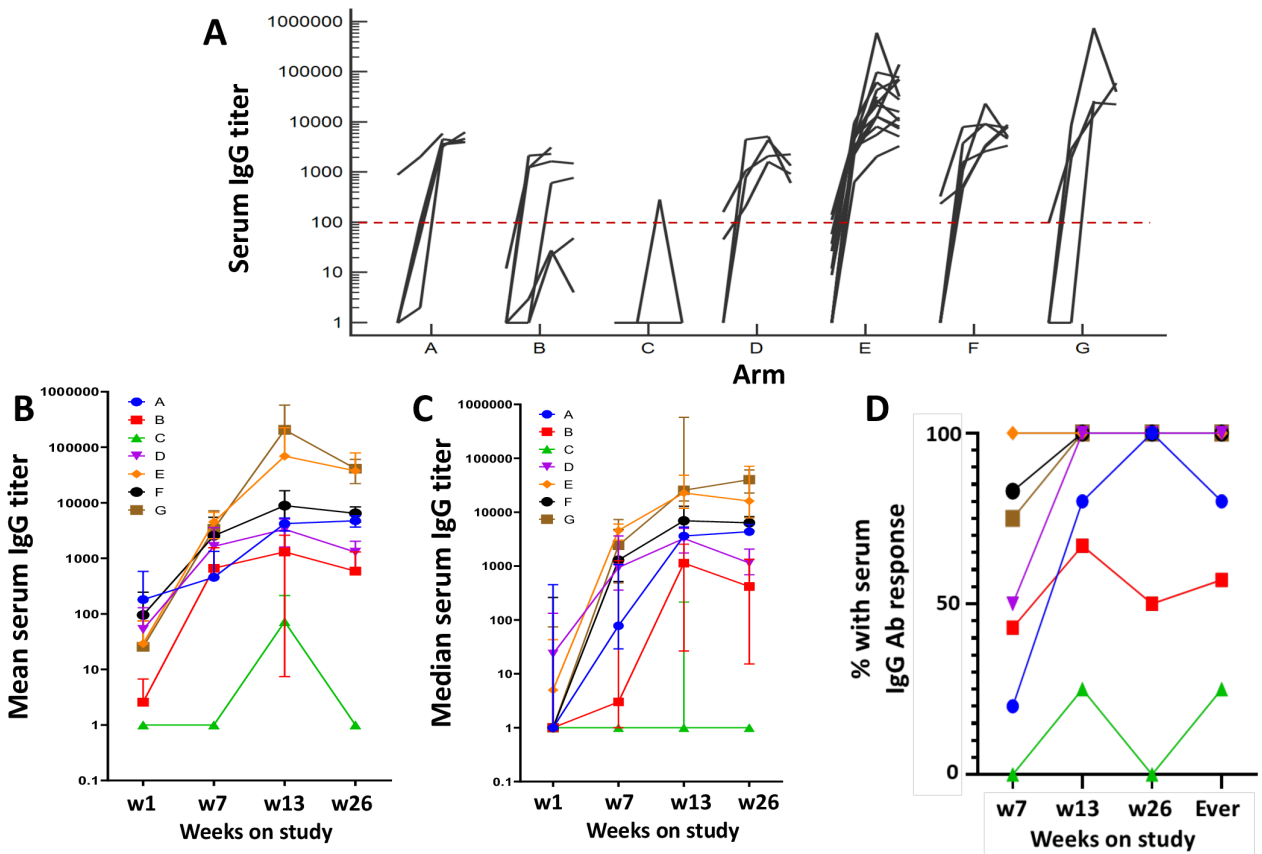

Figure 5 Serum IgG antibody response to LPV7 peptides. Serum Ab titers over time are shown for participants in arms A-G, representing 5, 7, 4, 4, 14, 6, and 4 participants, respectively (A). Also, the mean $\pm \mathrm{SD}$ (B) and median plus IQR (C) values for each arm are plotted over time. Panel (D) shows the cumulative proportion in the study with an Ab response by each time point. 
However, differences were noted in $\mathrm{T}$ cell immune response by institution, details for which are in online supplemental table 5 . All T cell responses to LPV7 and to MEP were observed for participants treated at Institution 1 , the site where immune analyses were performed. Most responses to Tet were also observed at Institution 1, but some were observed at Institution 2. The proportions with $\mathrm{T}$ cell responses by institution are shown in online supplemental figures 2A, B. Blood samples were shipped overnight from Institution 2 to Institution 1; thus, the possibility that shipping conditions may have reduced $\mathrm{T}$ cell viability and function was explored. Controls for each analysis included response to two mitogens (phytohemagglutinin (PHA) and phorbol myristate acetate (PMA) plus ionomycin) as well as a pool of over 30 short peptides from viral proteins (CMV, EBV, influenza) restricted by Class I MHC molecules (CEF peptides). The number of cells producing IFN-gamma in response to CEF peptides varied widely among participants, which is expected, but ranges appear similar between institutions (online supplemental figure 2C, D). PMA responses also were similar between sites: $\mathrm{p}=0.93$ (median 1534 vs 1427 per $100,000)$. However, the responses to PHA for Institution 2 were significantly lower than for Institution $1(\mathrm{p}=0.027$; median 181 (95\% CI 129 to 231)) vs 265 (214 to 326) (online supplemental figure 2C, D). Interestingly, the serum IgG (antibody) response to the LPV7 peptides was high for both sites, without appreciable differences in response frequency or magnitude (online supplemental figure $2 \mathrm{E}-\mathrm{G}$ ). Thus, participants at both institutions did receive vaccines and developed immune responses.

We had performed two prior multicenter clinical trials of melanoma vaccines incorporating 12) Class I MHCrestricted peptides (12MP) plus Class II MHC-restricted peptides (either Tet or six melanoma helper peptides, 6MHP):Mel $43^{37}$ and Mel44. ${ }^{15}$ To explore whether this difference in IRR by institution had been observed previously, we reviewed the data on IRRs as a function of institution and found that in both of those trials, the IRRs were comparable across all sites, including the two institutions participating in the current trial (online supplemental figure 3 ).

\section{Clinical outcomes}

With a median follow-up of 4.7 years, 43 (86\%) of patients remain alive, with $32(64 \%)$ without known disease recurrence. For arms with IFA-containing adjuvants (A, E, F, $\mathrm{G})$, recurrences have occurred in 11/33 (33\%, 90\% CI 20 to 49$)$, vs $7 / 17$ ( $41 \%, 90 \%$ CI 21 to 64$)$ in those without IFA. Deaths due to melanoma have occurred in $3 / 33$ with IFA $(9 \%, 90 \%$ CI 3 to 22$)$ vs $4 / 17(24 \%, 90 \%$ CI 8 to 46) without IFA (arms B, C, D). Kaplan-Meier plots for disease-free and overall survival in the whole study population are shown in online supplemental figure 4 .

\section{DISCUSSION}

This study was initiated to assess safety and immunogenicity of vaccination with long peptides with each of seven adjuvant combinations and to select an adjuvant combination to use in future studies. LPV7 plus Tet was welltolerated across all adjuvant combinations with only one DLT. All other AEs were expected and consistent with prior vaccine studies. Ulceration at the vaccine site was identified in three participants $(6 \%)$ which is lower than with prior trials using short peptides and more than with helper peptides. ${ }^{38}$ There were significant positive associations between IRR and severity of local and overall TRAEs (online supplemental figure 1), suggesting that the extent of immune response may enhance inflammation locally and systemically.

A rationale for using long peptides is the requirement for internalization and presentation by APC, avoiding tolerogenic potential of MEPs binding directly to Class I MHC on cells such as fibroblasts and keratinocytes. ${ }^{9}$ Also, in vaccines containing IFA in mice, long peptides escape the negative effects of chronic inflammation in the vaccine site microenvironment (VSME) that may diminish immunogenicity of MEPs. ${ }^{8}$ In prior clinical trials with 12MP plus Tet in IFA alone (Mel43 ( $\mathrm{n}=60)$ and Mel44 $(\mathrm{n}=41))$, we observed $\mathrm{CD}^{+} \mathrm{T}$ cell responses ex vivo to at least one peptide by ELIspot assay in $73 \%$ and $78 \%$ of evaluable patients, respectively. ${ }^{14}{ }^{15} \mathrm{CD}^{+} \mathrm{T}$ cell responses to MEPs in the present trial did not exceed those IRRs, with only $18 \%$ overall, including $24 \%$ of all 33 participants receiving IFA as part of the adjuvant. The six peptides selected from 12MP included the most immunogenic in the prior Mel44 trial (online supplemental figure 4). ${ }^{15}$ The CD8 T cell response rates to each of the six MEPs from 12MP are lower than expected from the Mel44 trial (). Thus, lower CD8 T cell responses to the MEPs may be due to factors other than the choice of peptide and may be due to any of several factors:

- The present trial differed from the prior trials by administering vaccines 4-6 every 3 weeks, rather than weekly. However, most immune responses are evident after the first three vaccines; so, this schedule change is not likely to explain the difference. Also, high IRRs have been observed in other trials with vaccines 4-6 administered every 3 weeks. ${ }^{39} 40$

- In some of our prior trials, vaccines were administered to the same vaccine site each week (same site vaccination, SSV), but vaccines were rotated to different skin sites each week in the present trial. We have found that SSV can induce tertiary lymphoid structures and enhance Th1 dominance in the VSME. ${ }^{41}{ }^{42}$ These may be crucial for optimal immunogenicity, and further investigation is underway to understand the role of SSV.

- Surprisingly, almost all detected $\mathrm{T}$ cell responses were observed in participants treated at Institution 1 , where the immune analyses were performed. This difference may be explained partially by negative impacts of PBMC shipping overnight from Institution 
2, but preserved responses to PMA and CEF peptides suggests that most $\mathrm{T}$ cell function was preserved. We have previously noted that temperature conditions during shipping can affect PBMC recovery. ${ }^{43}$ Exposure to $40^{\circ} \mathrm{C}$ for more than 8 hours, as is a common shipping occurrence from Institution 2, results in reduced cell recovery and cell viability. Within Institution 1 patients only, the IRRs to LPV7 were as high as $71 \%(5 / 7)$ for Arm E and 100\% (4/4) for Arm G, and IRRs to MEPs were highest for Arm E (57\%, 4/7), which are more favorable than for the whole study population. Even if only reviewing that data for Institution 1, the findings of favorable immunogenicity with IFA+polyICLC are supported and the more favorable immunogenicity with addition of IFA to TLR agonists overall (online supplemental figure 2A).

The IRRs to Tet exceeded $90 \%$ in prior trials; ${ }^{14}{ }^{15}$ thus, the overall $40 \%$ IRR to Tet in the present trial, despite adding TLR agonists in most arms, is lower than expected and suggests a need for further optimization. Tet was added because it was not initially known if LPV7 alone would induce strong $\mathrm{CD}^{+} \mathrm{T}$ cell responses. The overall IRR to LPV7 may include both $\mathrm{CD}^{+}$and $\mathrm{CD}^{+} \mathrm{T}$ cell responses. These were observed ex vivo in $30 \%$ of participants overall. Serum Ab responses to LPV7 were detected in a much higher proportion of participants (84\%). Now that we have data that LPV7 alone is sufficient to induce both $\mathrm{CD}^{+}$and $\mathrm{CD} 4^{+} \mathrm{T}$ cell responses, use of Tet may not be necessary going forward. Still, tetanus toxoid can modulate responses in the VSME and help support immune responses to less immunogenic melanomaspecific peptides.

The lack of detectable $\mathrm{T}$ cell responses in samples from Institution 2 may reflect artifactual lack of reactivity there, and it raises the possibility that the $\mathrm{T}$ cell response rates at Institution 1 are more reflectively of the true $\mathrm{T}$ cell response rates. If so, then the overall IRR to LPV7 may be closer to $48 \%$ overall, and to $67 \%$ for those patients vaccinated with IFA-containing adjuvants, as shown for Institution 1 in online supplemental table 5 . Similarly, the CD8 $\mathrm{T}$ cell response rate to MEP after vaccination with LPV7 in IFA containing adjuvants may be closer to the $44 \%$ observed at Institution 1. Supporting this is the finding of $\mathrm{T}$ cell responses to Tetanus peptide in $72 \%$ of patients vaccinated with IFA-containing adjuvants at Institution 1, which is closer to what has been observed in other trials.

We have previously demonstrated that $\mathrm{Ab}$ responses to melanoma helper peptides are associated with induction of T-cell responses and with improved overall survival. ${ }^{44}$ Since Abs will not bind directly to antigen on tumor cells but rather to epitopes of intracellular antigens presented in the context of MHC, they may opsonize the vaccine peptides to enhance DC presentation and activation of $\mathrm{T}$ cells. Abs can also opsonize intracellular proteins after cell death and support cross-presentation of proteins released by dying tumor cells. More work is being done in this area to understand this phenomenon and optimize the application of immune monitoring using $\mathrm{Ab}$ responses.
Among the monotherapy adjuvant strategies (Zone 1, online supplemental table 1), T cell IRRs to LPV7 were higher with IFA alone than with either TLR agonist alone. For vaccines with doublet adjuvants (Zone 2), the highest IRR was with LPV7 with IFA plus polyICLC. With all three adjuvants (Arm G), T cell responses to LPV7 were detected in four of six participants (67\%) but with only one demonstrable CD8 T cell response to MEPs. Across all cohorts, those including IFA induced IRRs for T cells and $\mathrm{Ab}$ that trended higher than those lacking adjuvant combinations lacking IFA (figure 5 and table 2). Vaccines including IFA also were associated with favorable clinical outcomes thus far.

This trial used a novel adaptive design that enabled assessment of safety and immunogenicity across seven different vaccine adjuvants with lower enrollment than would be required if it were a traditional 7-arm randomized study. The adaptive design limited exposure of participants to less immunogenic regimens. However, the small number of participants enrolled in most arms limits the precision of the immune response estimates. Arm E enrolled the most participants (16) and was among the most immunogenic approaches. Arm $\mathrm{G}$ also generated favorable IRRs, but it is not clear that adding resiquimod significantly enhances immunogenicity over the regimens without resiquimod. The evaluation of adjuvants containing IFA versus those without IFA is an unplanned analysis and may be considered exploratory only. However, it supports continued use of IFA as an adjuvant for peptide vaccines in humans, contradicting a trend based on murine data. The present study did not evaluate agonists for TLR9, which have shown value for enhancing the immunogenicity of peptides when added to IFA. ${ }^{19}$ This and other agents also offer promise. Preclinical data also strongly support the use of CD40 antibodies plus TLR agonists administered directly with peptide vaccines, ${ }^{45}$ and this has not yet been tested in humans, but remains another promising strategy. In future studies, we would like to explore these approaches and analyses of additional cytokines as well as functional assays of non-IFNgamma activity, chemokine receptors such as CXCR3, and other homing receptors such as cutaneous lymphocyte antigen and $\alpha 4 \beta 7$ integrin expression as demonstrated in previous work. ${ }^{39} 46$ Curiously, IRRs do not always correlate with intratumoral responses. There is very little information on whether $\mathrm{T}$ cells induced by cancer vaccines infiltrate tumors, The present study was performed in patients without measurable tumor deposits; so, those analyses were not feasible in the present study. Such studies are important to address in future studies that incorporate tumor biopsies prevaccination and postvaccination.

A major focus of current vaccine development is on mutated neoantigens, which show promise, but their activity is limited by lack of consensus on the best way to induce immune responses to these and other cancer antigens. Thus, there is a critical need to define the best vaccine adjuvants to use with these and other cancer vaccines. The present study contributes to an enhanced 
understanding and provides direction toward optimized cancer vaccine approaches by demonstrating safety and immunogenicity of seven new long peptides, some of which may be useful beyond melanoma, by confirming the safety and immunogenicity of vaccination with IFA+polyICLC, and by raising new questions about the role of same-site vaccination that deserve further investigation and may enhance the effectiveness of cancer vaccines.

\author{
Author affiliations \\ ${ }^{1}$ The University of Texas MD Anderson Cancer Center, Houston, Texas, USA \\ ${ }^{2}$ University of Virginia School of Medicine, Charlottesville, Virginia, USA \\ ${ }^{3}$ Public Health Sciences, University of Virginia School of Medicine, Charlottesville, \\ Virginia, USA \\ ${ }^{4}$ Icahn School of Medicine at Mount Sinai, New York, New York, USA \\ ${ }^{5}$ Moffitt Cancer Center, Tampa, Florida, USA \\ ${ }^{6}$ Department of Surgery, University of Virginia, Charlottesville, Virginia, USA
}

\section{Twitter Sapna P Patel @DrSapnaPatel}

Acknowledgements We thank the Cancer Research Institute/Ludwig Institute for Cancer Research for kindly providing the polyICLC and the long NY-ESO-1 peptide and $3 \mathrm{M}$ for providing resiquimod.

Contributors All authors contributed to work either in conception, execution, specimen analysis, statistical analysis, or manuscript writing. All authors reviewed and approved the final version of the manuscript.

Funding SPP has received research support from ImmmunoMet and Oncoceutics; institutional research funding from Bristol Myers Squibb, Deciphera, Foghorn Therapeutics, InxMed, Novartis, Provectus, Reata, and TriSalus Life Sciences; served as IDMC Chair for Immunocore; served as DSMC Chair for Reata; received honoraria as a non-promotional speaker for Merck; served on advisory boards for Cardinal Health, Castle Biosciences, and TriSalus Life Sciences. SG has received grants from Regeneron, BMS, Takeda, and Janssen R\&D; personal consulting fees from OncoMed and Merck; and has a patent on NY-ESO-1 peptide formulations. PH has served on advisory boards for Dragonfly and Sanofi; and served as a consultant for Immatics and GlaxoSmithKline. CLS has received institutional research support from Celldex, Glaxo-Smith Kline, Merck, 3M, Theraclion, and Polynoma; served on advisory boards for Immatics and CureVac; received licensing fee payments through the UVA Licensing and Ventures Group for patents for peptides used in cancer vaccines.

Competing interests CLS has the following disclosures: research support to the University of Virginia from Celldex (funding, drug), Glaxo-Smith Kline (funding), Merck (funding, drug), 3M (drug), Theraclion (device staff support); Funding to the University of Virginia from Polynoma for PI role on the MAVIS Clinical Trial; Funding to the University of Virginia for roles on Scientific Advisory Boards for Immatics and CureVac. Also, CLS receives licensing fee payments through the UVA Licensing and Ventures Group for patents for peptides used in cancer vaccines.

Patient consent for publication Not required.

Provenance and peer review Not commissioned; externally peer reviewed.

Data availability statement Data are available on reasonable request. All data relevant to the study are included in the article or uploaded as supplementary information. All data relevant to the study are included in the article or uploaded as supplementary information and are available on request to the senior author.

Supplemental material This content has been supplied by the author(s). It has not been vetted by BMJ Publishing Group Limited (BMJ) and may not have been peer-reviewed. Any opinions or recommendations discussed are solely those of the author(s) and are not endorsed by BMJ. BMJ disclaims all liability and responsibility arising from any reliance placed on the content. Where the content includes any translated material, BMJ does not warrant the accuracy and reliability of the translations (including but not limited to local regulations, clinical guidelines, terminology, drug names and drug dosages), and is not responsible for any error and/or omissions arising from translation and adaptation or otherwise.

Open access This is an open access article distributed in accordance with the Creative Commons Attribution 4.0 Unported (CC BY 4.0) license, which permits others to copy, redistribute, remix, transform and build upon this work for any purpose, provided the original work is properly cited, a link to the licence is given, and indication of whether changes were made. See https://creativecommons.org/ licenses/by/4.0/.

\section{ORCID iDs}

Sapna P Patel http://orcid.org/0000-0003-1339-1517

Craig L Slingluff http://orcid.org/0000-0002-6664-4373

\section{REFERENCES}

1 Spiers L, Coupe N, Payne M. Toxicities associated with checkpoint inhibitors-an overview. Rheumatology 2019;58:p. vii7-16.

2 Novellino L, Castelli C, Parmiani G. A listing of human tumor antigens recognized by T cells: March 2004 update. Cancer Immunology, Immunotherapy 2005;54:187-207.

3 Schwartzentruber DJ, Lawson DH, Richards JM, et al. Gp100 peptide vaccine and interleukin-2 in patients with advanced melanoma. N Engl J Med 2011;364:2119-27.

4 Robbins PF, Kassim SH, Tran TLN, et al. A pilot trial using lymphocytes genetically engineered with an NY-ESO-1-reactive T-cell receptor: long-term follow-up and correlates with response. Clin Cancer Res 2015;21:1019-27.

5 Lu Y-C, Parker LL, Lu T, et al. Treatment of patients with metastatic cancer using a major histocompatibility complex class II-restricted Tcell receptor targeting the cancer germline antigen MAGE-A3. J Clin Oncol 2017;35:3322-9.

6 Hunder NN, Wallen $\mathrm{H}$, Cao J, et al. Treatment of metastatic melanoma with autologous CD4+ T cells against NY-ESO-1. N Engl J Med 2008;358:2698-703.

7 Slingluff CL, Petroni GR, Yamshchikov GV, et al. Immunologic and clinical outcomes of vaccination with a multiepitope melanoma peptide vaccine plus low-dose interleukin-2 administered either concurrently or on a delayed schedule. J Clin Oncol 2004;22:4474-85.

8 Hailemichael Y, Dai Z, Jaffarzad N, et al. Persistent antigen at vaccination sites induces tumor-specific CD8 ${ }^{+} \mathrm{T}$ cell sequestration, dysfunction and deletion. Nat Med 2013;19:465-72.

9 Bijker MS, van den Eeden SJF, Franken KL, et al. Cd8+ CTL priming by exact peptide epitopes in incomplete Freund's adjuvant induces a vanishing CTL response, whereas long peptides induce sustained CTL reactivity. J Immunol 2007;179:5033-40.

10 Kenter GG, Welters MJP, Valentijn ARPM, et al. Vaccination against HPV-16 oncoproteins for vulvar intraepithelial neoplasia. $N$ Engl J Med Overseas Ed 2009;361:1838-47.

11 Baumgaertner $\mathrm{P}$, Costa Nunes $\mathrm{C}$, Cachot $\mathrm{A}$, et al. Vaccination of stage III/IV melanoma patients with long NY-ESO-1 peptide and $\mathrm{CpG}-\mathrm{B}$ elicits robust $\mathrm{CD} 8^{+}$and $\mathrm{CD} 4^{+} \mathrm{T}$-cell responses with multiple specificities including a novel DR7-restricted epitope. Oncoimmunology 2016;5:e1216290.

12 Sabbatini P, Tsuji T, Ferran L, et al. Phase I trial of overlapping long peptides from a tumor self-antigen and poly-ICLC shows rapid induction of integrated immune response in ovarian cancer patients. Clin Cancer Res 2012;18:6497-508.

13 Kenter GG, Welters MJP, Valentijn ARPM, et al. Vaccination against HPV-16 oncoproteins for vulvar intraepithelial neoplasia. $N$ Engl J Med 2009;361:1838-47.

14 Slingluff CL, Petroni GR, Olson WC, et al. Effect of granulocyte/ macrophage colony-stimulating factor on circulating CD8+ and CD4+ T-cell responses to a multipeptide melanoma vaccine: outcome of a multicenter randomized trial. Clin Cancer Res 2009;15:7036-44.

15 Slingluff CL, Petroni GR, Chianese-Bullock KA, et al. Randomized multicenter trial of the effects of melanoma-associated helper peptides and cyclophosphamide on the immunogenicity of a multipeptide melanoma vaccine. J Clin Oncol 2011;29:2924-32.

16 Schwartzentruber DJ, Lawson D, Richards J, et al. A phase III multi-institutional randomized study of immunization with the gp100: 209-217(210M) peptide followed by high-dose IL-2 compared with high-dose IL-2 alone in patients with metastatic melanoma. J Clin Oncol 2009;27:CRA9011.

17 Melssen MM, Petroni GR, Chianese-Bullock KA, et al. A multipeptide vaccine plus Toll-like receptor agonists LPS or polyICLC in combination with incomplete Freund's adjuvant in melanoma patients. J Immunother Cancer 2019;7:163.

18 Slingluff, Jr. CL, Petroni GR, Chianese-Bullock KA, et al. Trial to evaluate the immunogenicity and safety of a melanoma helper peptide vaccine plus incomplete Freund's adjuvant, cyclophosphamide, and polyICLC (Mel63). J Immunother Cancer 2021;9:e000934.

19 Speiser DE, Liénard D, Rufer N, et al. Rapid and strong human $\mathrm{CD} 8+\mathrm{T}$ cell responses to vaccination with peptide, IFA, and CpG oligodeoxynucleotide 7909. J Clin Invest 2005;115:739-46. 
20 Ahonen CL, Wasiuk A, Fuse S, et al. Enhanced efficacy and reduced toxicity of multifactorial adjuvants compared with unitary adjuvants as cancer vaccines. Blood 2008;111:3116-25.

21 Colletti NJ, Liu H, Gower AC, et al. TIr3 signaling promotes the induction of unique human BDCA-3 dendritic cell populations. Front Immunol 2016;7:88.

22 Tel J, Sittig SP, Blom RAM, et al. Targeting uptake receptors on human plasmacytoid dendritic cells triggers antigen crosspresentation and robust type I IFN secretion. J Immunol 2013;191:5005-12.

23 Gorden KKB, Qiu XX, Binsfeld CCA, et al. Cutting edge: activation of murine TLR8 by a combination of imidazoquinoline immune response modifiers and polyT oligodeoxynucleotides. J Immunol 2006;177:6584-7.

24 Block MS, Nevala WK, Pang Y-P, et al. A pilot clinical trial testing topical resiquimod and a xenopeptide as immune adjuvants for a melanoma vaccine targeting MART-1. Melanoma Res 2019;29:420-7.

25 Lee M, Park C-S, Lee Y-R, et al. Resiquimod, a TLR7/8 agonist, promotes differentiation of myeloid-derived suppressor cells into macrophages and dendritic cells. Arch Pharm Res 2014;37:1234-40

26 Chang BA, Cross JL, Najar HM, et al. Topical resiquimod promotes priming of CTL to parenteral antigens. Vaccine 2009;27:5791-9.

27 Sabado RL, Pavlick A, Gnjatic S, et al. Resiquimod as an immunologic adjuvant for NY-ESO-1 protein vaccination in patients with high-risk melanoma. Cancer Immunol Res 2015;3:278-87.

28 Pearson FE, Chang K, Minoda Y, et al. Activation of human CD141 and CD1 $\mathrm{c}^{+}$dendritic cells in vivo with combined TLR3 and TLR7/8 ligation. Immunol Cell Biol 2018;96:390-400.

29 Matthews K, Chung NPY, Klasse PJ, et al. Clinical adjuvant combinations stimulate potent B-cell responses in vitro by activating dermal dendritic cells. PLoS One 2013;8:e63785.

30 Wages NA, Slingluff CL, Petroni GR. Statistical controversies in clinical research: early-phase adaptive design for combination immunotherapies. Ann Oncol 2017;28:696-701.

31 Slingluff CL, Petroni GR, Chianese-Bullock KA, et al. Immunologic and clinical outcomes of a randomized phase II trial of two multipeptide vaccines for melanoma in the adjuvant setting. Clin Cancer Res 2007:13:6386-95.

32 Slingluff CL, Yamshchikov G, Neese P, et al. Phase I trial of a melanoma vaccine with gp100(280-288) peptide and tetanus helper peptide in adjuvant: immunologic and clinical outcomes. Clin Cancer Res 2001;7:3012-24.

33 Currier JR, Kuta EG, Turk E, et al. A panel of MHC class I restricted viral peptides for use as a quality control for vaccine trial ELISPOT assays. J Immunol Methods 2002;260:157-72.
34 O'Quigley J, Pepe M, Fisher L. Continual reassessment method: a practical design for phase 1 clinical trials in cancer. Biometrics 1990;46:33-48.

35 Wages NA, Conaway MR, O'Quigley J. Dose-Finding design for multi-drug combinations. Clin Trials 2011;8:380-9.

36 Wages NA, Slingluff CL, Petroni GR. A phase I/II adaptive design to determine the optimal treatment regimen from a set of combination immunotherapies in high-risk melanoma. Contemp Clin Trials 2015;41:172-9.

37 Slingluff C, Petroni G, Chianese-Bullock K. Effects of melanomaderived helper peptides and cyclophosphamide on the immunogenicity of a multipeptide melanoma vaccine. Journal of Immunotherapy 2009;32:976.

$38 \mathrm{Hu}$ Y, Smolkin ME, White EJ, et al. Inflammatory adverse events are associated with disease-free survival after vaccine therapy among patients with melanoma. Ann Surg Oncol 2014;21:3978-84.

39 Mauldin IS, Wages NA, Stowman AM, et al. Topical treatment of melanoma metastases with imiquimod, plus administration of a cancer vaccine, promotes immune signatures in the metastases. Cancer Immunol Immunother 2016;65:1201-12.

40 Mauldin IS, Wages NA, Stowman AM, et al. Intratumoral interferongamma increases chemokine production but fails to increase $T$ cell infiltration of human melanoma metastases. Cancer Immunol Immunother 2016;65:1189-99.

41 Harris RC, Chianese-Bullock KA, Petroni GR, et al. The vaccinesite microenvironment induced by injection of incomplete Freund's adjuvant, with or without melanoma peptides. J Immunother 2012;35:78-88.

42 Schaefer JT, Patterson JW, Deacon DH, et al. Dynamic changes in cellular infiltrates with repeated cutaneous vaccination: a histologic and immunophenotypic analysis. J Trans/ Med 2010;8:79.

43 Olson WC, Smolkin ME, Farris EM, et al. Shipping blood to a central laboratory in multicenter clinical trials: effect of ambient temperature on specimen temperature, and effects of temperature on mononuclear cell yield, viability and immunologic function. $J$ Transl Med 2011;9:26.

44 Reed CM, Cresce ND, Mauldin IS, et al. Vaccination with melanoma helper peptides induces antibody responses associated with improved overall survival. Clin Cancer Res 2015;21:3879-87.

45 Sanchez PJ, McWilliams JA, Haluszczak C, et al. Combined TLR/CD40 stimulation mediates potent cellular immunity by regulating dendritic cell expression of CD70 in vivo. J Immunol 2007;178:1564-72.

46 Clancy-Thompson E, King LK, Nunnley LD, et al. Peptide vaccination in Montanide adjuvant induces and GM-CSF increases CXCR3 and cutaneous lymphocyte antigen expression by tumor antigen-specific CD8 T cells. Cancer Immunol Res 2013;1:332-9. 